\title{
Breakfast consumption habits among schoolchildren: A cross-sectional study in Riyadh, Saudi Arabia
}

\author{
Maha Al Turki ${ }^{1 *}$, Sarah Al Shloi ${ }^{1}$, Alhanouf Al Harbi ${ }^{1}$, Alanoud Al Agil ${ }^{1}$, Winnie Philip ${ }^{1}$ and \\ Shoeb Qureshi ${ }^{2}$
}

${ }^{1}$ Clinical Nutrition Program, King Saud bin Abdulaziz University for Health Sciences, Mail Code 3129, P.O Box 3660, Riyadh 11481, Saudi Arabia.

${ }^{2}$ Research Unit, College of Applied Medical Sciences, King Saud bin Abdulaziz University for Health Sciences, Riyadh, Saudi Arabia.

Accepted 15 June, 2018

\begin{abstract}
Evidence suggests that breakfast consumption can enhance cognitive and psychosocial function, academic performance, and school attendance of schoolchildren. Also, there is some evidence to suggest that children who frequently skip breakfast have a higher risk of being obese compared to those children that regularly consume breakfast. There is a growing body of literature that recognizes the importance of this meal for school children. However, a limited number of researchers have explored the breakfast habits among Saudi young school children. We assessed breakfast consumption habits, food preferences and student perspectives concerning breakfast consumption among young Saudi female students living in Riyadh city. A cross-sectional study of 384 female primary school students was conducted in 2016 . Four schools each from government and private sector, located in different zones of Riyadh were randomly selected for the study. Age, anthropometric measurements, health status of the students, and information regarding breakfast habits and preferred food choices were collected. Mean and standard deviation (SD) was used to present continuous data. Categorical data was presented in frequencies and percentages. To compare the difference in means, independent $t$-test was also used. Statistical Package for Social Sciences (SPSS version 22) was used for the analysis of data. A $p$ value of less than 0.05 was considered statistically significant. Eighty-eight percent of schoolchildren reported that they consume breakfast, with only $2 \%$ having regular breakfast more than four days a week. The mean $( \pm S D)$ age of those who consume breakfast was significantly lower than those who usually skipped breakfast. Milk and dairy products and/or carbohydrates were the preferred breakfast food choice of most schoolchildren. Although, only $12 \%$ of the schoolchildren in the sample reported not to consume breakfast, the majority of the rest of the students reported not to be frequent breakfast consumers (<four times per the whole week). The prevalence of breakfast skipping among primary school students statistically increase with age. It is ultimately the responsibility of parents to ensure that young children are eating breakfast, and so it is crucial to make sure that such parents are educated on the benefits of this meal for their children. School health and nutritional programs are recommended to improve dietary practices and nutritional awareness for schoolchildren.
\end{abstract}

Keywords: Breakfast consumption, breakfast food choices, school, children, Saudi Arabia.

*Corresponding author. E-mail: Alturkimahaa@gmail.com. Tel: +966544699924.

\section{INTRODUCTION}

There is a consensus that eating breakfast has many health benefits for children by replenishing energy stores and giving a well-needed glucose boost after several hours of fasting (World Health Organization and UNICEF, 2003). Indeed, it has long been recognized in Europe that starving children struggle during the learning process 
(Arndt, 2013). Earlier studies have reported an association between the consumption of breakfast with enhancing cognitive and psychosocial functions, academic performance, and school attendance (Pollitt, 1995). In addition, there is some evidence to suggest that children who frequently skip breakfast have a higher risk of being obese compared to those having breakfast regularly (Pollitt and Mathews, 1998; Rogério et al., 2016). A previous study has reported that the prevalence of obesity among children in Saudi Arabia is on the rise, with Al Shehri et al. (2013) revealing that obesity level amongst school age children in Saudi Arabia have now reached $9.3 \%$ (roughly one in 10 Saudi children), with $23 \%$ considered to be overweight, and recommending a national strategy to treat and prevent serious health problems that may result from childhood obesity (Al Shehri et al., 2013). Furthermore, Al-Dossary et al. (2010) also reported that a high prevalence of overweight and obese children in all age groups and in all areas in Saudi Arabia has been confirmed through a few surveys.

Alenazi et al. (2014) studied the effects of regular homemade breakfast on body mass index (BMI) of male children in a Northern region of Saudi Arabia. It was found that the regular consumption of breakfast for children resulted in a higher chance of a normal BMI. Moreover, Al-Hazzaa et al. (2012) also provided some evidence that Saudi adolescents are less at risk from obesity if they regularly consume breakfast. However, it is conceded that there are many other factors at play in obesity, such as the type of food consumed (and especially the amount of vegetables in the diet) and activity levels (Vilchis-Gil et al., 2015). Therefore, creating a higher awareness of the benefits of eating breakfast for children may effectively tackle childhood obesity problem in Saudi Arabia. Nevertheless, to create a national strategy for Saudi Arabia in respect of the problem of childhood obesity, perhaps more empirical studies are needed in this area, particularly on breakfast consumption habits including food preference, so that any such strategies are strongly supported with empirical evidence. The aim of the present study is to explore the breakfast consumption habits and food choices amongst a sample of young female students in the center of Riyadh, the most populous area in Saudi Arabia. Furthermore, the student's perspective on their breakfast consumption habits was investigated in this study.

\section{MATERIALS AND METHODS}

Ethical clearance for the current study was obtained from King Abdullah International Medical Research Centre (KAIMRC) in September 2016 (Ref. No. RYD-16-419812-139269). Permission to carry out the study in schools was obtained from the Saudi Ministry of Education and the school administrations. Consent forms were sent to the parents of the schoolchildren before including them in the study.

The total population of female students enrolled in the schools in Riyadh city in 2016-2017 was 291132 students, according to the
Saudi Ministry of Education (MOE). With a margin of error of $5 \%$ and $95 \%$ confidence level, the minimum required sample size was determined to be 384 . A cross-sectional study of 384 female students aged between 6 and 12 years old was conducted at four major primary schools in Riyadh city from September 2016 to November 2016. To ensure that students from different socioeconomic status were included, these four schools, either public or private, and located in different zones of Riyadh were randomly selected for the study. Forty-eight students from each school were selected by stratified random sampling to form the total required sample. Then all students selected from each school were included in the study.

A parent-reported health status record was used to include healthy schoolchildren who have no physical disability or learning disorders. A list of eligible students $(n=384)$ was prepared and a consent form was sent to their parents. Students who did not provide their parents' consent on the data collection day were excluded. After parents' approval, BMI and breakfast habits were assessed for each student.

Age and parent-reported health status of the students were obtained from school records. Weight and height were measured using an electronic body scale. Schoolchildren's BMI was calculated as weight in kilogram $(\mathrm{kg})$ divided by the height in meter square $\left(\mathrm{m}^{2}\right)$. Age, sex, weight and height data were used to establish BMI percentile (5th, 10th, 25th, 50th, 75th, 90th, and 95th) for each student. BMI percentile categories were produced by rounding the percentile to the nearest categorical threshold.

Breakfast habit was assessed using a self-reported screening questionnaire of 11 questions on the frequency, reasons and effects of skipping breakfast (Khan, 2011). The content validity of the questionnaire was checked using field experts' panel to assess the relevancy of the questionnaire to the outcomes and check the clarity of questions. Later we asked another two clinical nutritionists to evaluate the simplicity and transparency of the questions and to provide independent reports.

Data about usual breakfast habits, weekly frequency of breakfast habits, food choices for breakfast, reasons for skipping breakfast and the impact of consuming/skipping breakfast were collected using this questionnaire.

Students completed the questionnaire in the classroom after receiving a verbal description of the study prior to participation. Based on their age, students were divided into two groups to complete the breakfast habits questionnaire. Researchers interviewed younger students (6 to 8 years old), while older students (9 to 12 years old) completed the questionnaire themselves.

\section{Statistical analysis}

Mean and standard deviation (SD) was used to present continuous data. Categorical data was presented in frequencies and percentages. Pearson chi-square test was used to find any association between the categorical variables. To compare the difference in means, independent $t$-test was also used. Statistical Package for Social Sciences (SPSS version 22) was used for the analysis of data. A $p$ value of less than 0.05 was considered statistically significant.

\section{RESULTS}

\section{Characteristics of study population}

The characteristics of the participants are listed in Table 1. A total of 384 female students were enrolled in the study. Fifty percent (192) of them were from public school 
Table 1. Characteristics of the study populations $(n=384)$.

\begin{tabular}{lc}
\hline Characteristics & Mean \pm SD \\
Age (years) & $9.15 \pm 1.76$ \\
Weight $(\mathrm{kg})$ & $32.12 \pm 11.07$ \\
Height $(\mathrm{cm})$ & $132.79 \pm 11.70$ \\
BMI Percentile & $54.65 \pm 33.73$ \\
& \\
BMI percentile classification ${ }^{*}\left(\mathbf{k g} / \mathbf{m}^{2}\right)$ & $\boldsymbol{n}(\%)$ \\
Underweight & $33(8.6)$ \\
Normal & $237(61.7)$ \\
Overweight & $51(13.3)$ \\
Obese & $63(16.4)$ \\
& \\
School grade distribution & \\
Grade 1 & $66(17.2)$ \\
Grade 2 & $64(16.7)$ \\
Grade 3 & $68(17.7)$ \\
Grade 4 & $58(15.1)$ \\
Grade 5 & $58(15.1)$ \\
Grade 6 & $70(18.2)$ \\
\hline
\end{tabular}

* $\leq 5 \%$ is underweight, $5-84 \%$ is normal, $85-95 \%$ is overweight, $\geq 95 \%$ is obese.

Table 2. Breakfast consumption habits according to age group, school type and BMI status.

\begin{tabular}{lcc}
\hline \multirow{2}{*}{ Group } & \multicolumn{2}{c}{ Breakfast consumption habits } \\
\cline { 2 - 3 } & Consumed breakfast, $\boldsymbol{n}(\%)$ & Skipped breakfast, $\boldsymbol{n}(\%)$ \\
\hline Age group & & $17(8.5)$ \\
6-9 years old $(n=201)$ & $184(91.5)$ & $28(15)$ \\
10-12 years old $(n=183)$ & $155(85)$ & \\
& & $17(9)$ \\
School type & $175(91)$ & $28(14.6)$ \\
Private $(n=192)$ & $164(85.4)$ & \\
Public $(n=192)$ & & $2(6)$ \\
& & $29(12)$ \\
BMl classification & $31(94)$ & $7(14)$ \\
Underweight $(n=33)$ & $208(88)$ & $7(11)$ \\
Normal $(n=237)$ & $44(86)$ & \\
Overweight $(n=51)$ & $56(89)$ & \\
Obese $(n=63)$ & &
\end{tabular}

*There is a statistically significant relationship between breakfast consumption and student's age ( $t=3.214$, $p$ value $=0.002$ )

and the rest were from private ones. The schoolchildren represented all school grade level at the primary school system. The mean $( \pm S D)$ age was $9.15 \pm 1.76$ years, and the mean $( \pm S D)$ BMI percentile was $54.65 \pm 33.73$. Most of the students $(61.7 \%, 237)$ were found to have a normal BMI, while $29.6 \%$ (114) had a BMI in the overweight/obese categories. Only $8.6 \%$ (33) of the students in this study were underweight.

\section{Breakfast consumption habits among schoolchildren}

Table 2 represents the breakfast consumption habits among schoolchildren according to age, school type and BMI. Overall, $88 \%$ of students (339) reported that they consume breakfast whereas $12 \%$ (45) confirmed that they skip this meal. When students were asked where they usually eat breakfast, $72 \%$ (268) of them reported 
that they have their breakfast at home, $26.1 \%$ (97) at school and only $1.9 \%$ (7) reported to have their breakfast in the car.

An independent $t$-test was conducted to assess the demographic factors associated with the habit of breakfast consumption and skipping. Statistically significant difference was found between age and breakfast consumption $(t=3.214, p=0.002)$. The mean age of those who consume breakfast was less (9.06 \pm 1.79 years) than those who did not usually consume breakfast (9.79 \pm 1.37 years). However, there was no statistically significant difference between breakfast consumption habits and school type or BMI status.

\section{Frequency of student's breakfast consumption per week $(n=339)$}

The weekly frequency of breakfast consumption was classified into three main categories (Table 3). Most students were not frequent breakfast consumers $(72.5 \%$, 246) reporting to have breakfast 3 to 4 times a week. Only $2.1 \%$ (7) reported to have breakfast more than four times a week. None of the underweight students reported frequent weekly intake of breakfast.

\section{Breakfast food choices among schoolchildren}

The students' breakfast food choice was assessed by asking about their regular choices for this meal. Most students $(78 \%, 301)$ reported that they prefer to consume milk and dairy products (cheese and yogurt), and $76.8 \%$ (295) reported to consume food items under the carbohydrates groups such as; bread, muffin, cereal and oatmeal (Table 4).

A higher percentage of students with normal BMI reported to consume milk and dairy products, fruit/fruit juice, vegetable/vegetable juice, and food items from the protein and carbohydrate groups compared to students with BMls outside the normal range. However, the difference in food choices between different BMI categories was not statistically significant.

\section{Student's perspective on breakfast consumption habits}

Among the 45 schoolchildren who reported to skip breakfast, the most cited reason was not feeling hungry $(35 \%, 49)$. Twenty one percent (30) stated lack of time in the morning is the reason for not consuming this meal while $17 \%$ indicated that they do not prefer the available food choices. Seven percent of the students reported skipping breakfast to avoid weight gain.

Of the 339 schoolchildren who reported to be breakfast consumers, $56 \%$ stated that they feel hungry, and $43 \%$ of them reported stomachache and $26 \%$ reported headache if they skipped breakfast. Having trouble in paying attention in the class and getting tired was also reported by $26 \%$ and $34 \%$ of the students, respectively.

\section{DISCUSSION}

The present study was designed to determine the breakfast habits in a sample of 384 female schoolchildren in Riyadh city. In our sample, $12 \%$ of the schoolchildren were breakfast skippers, which is in the range reported in a previous review of breakfast habits (10 to 30\%) (Albertson et al., 2009). Thirty three percent of the sample was found to be overweight or obese, and $8 \%$ of the schoolchildren were underweight, a higher percentage than what was reported among Saudi school children previously (Al Shehri et al., 2013; Al-Dossary et al., 2010; Al-Hazzaa et al., 2012).

In addition, although $88 \%$ of the students reported to consume breakfast regularly, the majority of the underweight (at 94\%) and obese children (at 89\%) reported that they usually skip breakfast. This indicate a positive correlation between not eating breakfast and having an abnormal BMl for female schoolchildren in this region of Saudi Arabia. A recent longitudinal analysis found also that skipping breakfast was highly associated with increasing abdominal obesity in primary schoolchildren (Traub et al., 2018). Such a finding supports the strategy of promoting breakfast consumption amongst schoolchildren as a way to tackle childhood obesity in Saudi Arabia.

Moreover, the results also found that children who do not consume breakfast tend to be in an older demographic (and this may be indicative of peer pressure). Of those who do eat breakfast; this is rarely an everyday occurrence, with most reporting eating breakfast 3 to 4 days a week, and very few children in the sample having breakfast more regularly. Several earlier studies have also found that the prevalence of skipping breakfast increases with children's age and those young females are more likely to skip breakfast than young males (Albertson et al., 2009; Al Bashtawy, 2017; Pantea-Stoian et al., 2018; Ghafari et al., 2017).

Of the students in our study, most breakfast eaters preferred milk, dairy products, and/or carbohydrates (such as bread, cereal, or oatmeal). Nevertheless, the differences in food choices did not prove to be of any statistical significance, which means that it is the act of eating, or not eating breakfast, that is the key, regardless of the content. The main reasons provided for not eating breakfast included not feeling hungry, not having enough time, or not having the preferred food choices available to them. It should also be noted that of those children who skipped breakfast, over half said that they felt hungry, almost half experienced stomach aches, and around a quarter experienced a headache. Moreover, they 
Table 3. Weekly frequency of breakfast consumption according to age group, school type and BMI status.

\begin{tabular}{lccc}
\hline Parameter & $\begin{array}{c}\text { Rarely (0-2 days/week) } \\
\boldsymbol{n}(\%)\end{array}$ & $\begin{array}{c}\text { Occasionally (3-4 days/week) } \\
\boldsymbol{n}(\%)\end{array}$ & $\begin{array}{c}\text { Frequently (5-7 days/week) } \\
\boldsymbol{n}(\%)\end{array}$ \\
\hline All groups $^{*}(n=339)$ & $86(25.4)$ & $246(72.5)$ & $7(2.1)$ \\
Age group & & & \\
6-9 years old $(n=184)$ & $44(23.9)$ & $137(74.5)$ & $3(1.6)$ \\
10-12 years old $(n=155)$ & $42(27.1)$ & $109(70.3)$ & $4(2.6)$ \\
School type & & & \\
Private $(n=173)$ & & $128(74)$ & \\
Public $(n=166)$ & $118(71.1)$ & $3(1.8)$ \\
& & & \\
BMl classification & $45(23.7)$ & & - \\
Underweight $(n=31)$ & & $24(77.4)$ & $5(2.4)$ \\
Normal $(n=208)$ & $7(22.6)$ & $148(71.2)$ & $1(2.3)$ \\
Overweight $(n=44)$ & $55(26.4)$ & $32(72.7)$ & $1(1.8)$ \\
Obese $(n=56)$ & $11(25)$ & $42(75)$ & \\
\hline
\end{tabular}

*Only students who reported to consume breakfast were included.

Table 4. Breakfast food choices based on different food groups among schoolchildren.

\begin{tabular}{|c|c|c|c|c|c|c|c|}
\hline \multirow[b]{2}{*}{ Food groups ${ }^{\star}$} & \multirow[b]{2}{*}{$\begin{array}{l}\text { Total } \\
\text { sample }\end{array}$} & \multicolumn{2}{|c|}{ Age group } & \multicolumn{4}{|c|}{ BMI classification } \\
\hline & & $\begin{array}{c}\text { 6-9 y } \\
(n=201)\end{array}$ & $\begin{array}{l}10-12 y \\
(n=183)\end{array}$ & $\begin{array}{l}\text { Underweight } \\
\quad(n=33)\end{array}$ & $\begin{array}{l}\text { Normal } \\
(n=237)\end{array}$ & $\begin{array}{c}\text { Overweight } \\
(n=51)\end{array}$ & Obese $(n=63)$ \\
\hline $\begin{array}{l}\text { Milk \& dairy } \\
\text { products }\end{array}$ & 301 (78.4\%) & 149 (49.5\%) & $152(50.5 \%)$ & 26 (8.6\%) & $187(62.1 \%)$ & $39(13 \%)$ & $49(16.3 \%)$ \\
\hline Protein group & $125(32.6 \%)$ & $57(45.6 \%)$ & $68(54.4 \%)$ & $11(8.8 \%)$ & $87(69.6 \%)$ & $11(8.8 \%)$ & $16(12.8 \%)$ \\
\hline Fruit/ fruit juice & $114(9.9 \%)$ & $56(49.1 \%)$ & $58(50.9 \%)$ & $12(10.5 \%)$ & $62(54.4 \%)$ & $15(13.2 \%)$ & $25(21.9 \%)$ \\
\hline $\begin{array}{l}\text { Vegetable/ } \\
\text { vegetable juice }\end{array}$ & $38(29.7 \%)$ & $16(42.1 \%)$ & $22(57.9 \%)$ & $3(7.9 \%)$ & $24(63.2 \%)$ & $4(10.5 \%)$ & $7(18.4 \%)$ \\
\hline $\begin{array}{l}\text { Carbohydrates } \\
\text { group }\end{array}$ & $295(76.8 \%)$ & $152(51.5 \%)$ & $143(48.5 \%)$ & $23(7.8 \%)$ & $187(63.4 \%)$ & 38 (12.9\%) & 47 (15.9\%) \\
\hline
\end{tabular}

*Participants were allowed to choose more than one option of food groups. Data are presented as frequency and percentage.

frequently had difficulty paying attention in class $(26 \%)$ and felt tired (34\%), which demonstrates how not consuming breakfast may impact the attentionconcentration of the schoolchildren, and over a long period, this could negatively impact their educational achievements, alongside their health. As such, it is imperative that Saudi parents are aware of such statistics and outcomes, so that they can better prepare their children for school by ensuring that they eat breakfast and are fueled and ready for their school day. Also, it may seem counterintuitive to give an overweight child more food if they are not eating breakfast, but research has shown that the consumption of breakfast does aid in reducing obesity by mitigating hunger and reducing snacking and eating later in the day (Kong et al., 2011; Baum et al., 2017).

\section{Conclusions}

Although only $12 \%$ of the schoolchildren in our study reported to not consume breakfast, the majority of the rest of the students reported not to be frequent breakfast consumers (<four times/week). The prevalence of breakfast skipping among primary school students increased with age. Normal BMI students tend to choose food items representing all food groups in their breakfast compared to students with BMI categories outside the normal range who had limited their choices to certain food groups.

It is recommended that Saudi Arabian parents are made more aware of such effects, and the reasons as to why children do not eat breakfast, so that they can do provide the foods that their children like, and enforce a 
regime and habit of eating breakfast before starting the school day. Furthermore, although there is a counterintuitive element to forcing an obese or overweight child to eat breakfast, parents need to also be made aware of findings that show a correlation between obesity and non-breakfast consumption, so that these false intuitions and assumption can be overcome. Since this study was conducted among females' students only, further studies that explore sex differences in breakfast habits and food preference are recommended. Health promotion interventions on breakfast consumption are also recommended for both students and parents.

\section{ACKNOWLEDGEMENTS}

We wish to express our appreciation to the Saudi Ministry of Education for giving us the opportunity to conduct this study among several schools in Riyadh City. We also confer special thanks to the school administrations and teachers for their valuable collaboration, good spirits, and for creating a great working environment for us during the data collection process. We would also like to express a heartfelt appreciation to all students for devoting their valuable time to be a part of the study.

\section{Availability of data and material}

The datasets used and/or analyzed during the current study are available from the corresponding author on reasonable request.

\section{Competing interests}

The authors declare that they have no competing interests.

\section{Funding}

This work was supported by the King Abdullah International Medical Research Center (KAIMARC)/Ministry of National Guard-Health Affairs, Saudi Arabia under Grant number RYD-16-419812139269.

\section{REFERENCES}

Al Bashtawy M, 2017. Breakfast eating habits among school children. J Pediatr Nurs, 36: 118-123.

Al Shehri A, Al Alwan I, Al Fattani A, 2013. Obesity among Saudi children. Saudi J Obes, 1: 3-9.

Albertson A, Affenito S, Bauserman R, Holschuh N, Eldridge A, Barton $B, 2009$. The relationship of ready-to-eat cereal consumption to nutrient intake, blood lipids, and body mass index of children as they age through adolescence. J Am Dietet Assoc, 109: 1557-1565.
Al-Dossary S, Sarkis P, Hassan A, Ezz El Rega M, Fouda A, 2010. Obesity in Saudi children: a dangerous reality. Eastern Mediterranean Health J; 16: 1003-1008.

Alenazi S, Ali H., Alshammary O, Alenazi M, Wazir F, 2014. Effect of breakfast on BMI in school children in Northern Border Region Saudi Arabia. Khyber Med Univ J, 6: 106-109.

Al-Hazzaa H, Abahussain N, Al-Sobayel H, Qahwaji D, Musaiger A, 2012. Lifestyle factors associated with overweight and obesity among Saudi adolescents. BMC Public Health, 12: 354.

Arndt AH, 2013. Breakfast: A History. USA: Rowman andLittlefield.

Baum J, Gaines B, Kubas G, Mitchell C, Russell S, 2017. Educational nutrition messaging at breakfast reduces snack intake and influences snack preferences in adult men and women. Appetite, 117: 67-73.

Ghafari M, Doosti-Irani A, Amiri M, Cheraghi Z, 2017. Prevalence of the skipping breakfast among the Iranian students: A review article. Iran J Public Health, 46(7): 882-889.

Khan A, 2011. The relationship between breakfast, academic performance and vigilance in school aged children (Master's thesis). Murdoch University, Perth, WA.

Kong A, Beresford S, Alfano C, Foster-Schubert K, Neuhouser $M$, Johnson D, McTiernan A, 2011. Associations between snacking and weight loss and nutrient intake among postmenopausal overweightto-obese women in a dietary weight loss intervention. J Am Dietet Assoc, 111: 1898-1903.

Pantea-Stoian A, Andronache LF, Hainarosie R, Paduraru DN, Badiu CD, Arsene A, Mehedintu C, Ditu G, Pituru SM, Orlov C, Oros M, Nitipir C, 2018. Dietary habits and lifestyle in school-aged children from Bucharest, Romania. J Mind Med Sci, 5(1):85-92.

Pollitt E, 1995. Does breakfast make a difference in school? J Am Dietet Assoc, 95: 1134-1139.

Pollitt E, Mathews R, 1998. Breakfast and cognition: an integrative summary. Am J Clin Nutr, 67: 804S-813S.

Rogério $\mathrm{P}$, Rodrigues M., Alves R, Margarida P, Santana S, Gama A, Padez C, 2016. Irregular breakfast habits are associated with children's increased adiposity and children's and parents' lifestylerelated behaviors: a population-based cross-sectional study. Nutrire, 41: 8 .

Traub M, Lauer R, Kesztyüs T, Wartha O, Steinacker JM, Kesztyüs D, 2018. Skipping breakfast, overconsumption of soft drinks and screen media: longitudinal analysis of the combined influence on weight development in primary schoolchildren. BMC Public Health, 18:363.

Vilchis-Gil J, Galván-Portillo $M$, Klünder-Klünder M, Cruz M, FloresHuerta S, 2015. Food habits, physical activities and sedentary lifestyles of eutrophic and obese school children: a case-control study.BMC Public Health, 15: 124

World Health Organization, UNICEF, 2003. Global Strategy for Infant and Young Child Feeding. Geneva: World Health Organization.
Citation: Al Turki M, Al Shloi S, Al Harbi A, Al Agil A, Philip W, Qureshi $S$, 2018. Breakfast consumption habits among schoolchildren: $A$ cross-sectional study in Riyadh, Saudi Arabia. Int Res J Med Med Sci, 6(2): 50-55. 